\title{
PROFILE: GBSR DUO
}

The duo of George Barton (percussion) and Siwan Rhys (piano) is acquiring a reputation for exceptional interpretations of the existing pianopercussion repertoire, wellchosen commissions and committed performances of new works. With a keen emphasis on commissioning and repertoire-building complemented by the respect and trust of composers, recent world premieres include works from Arne

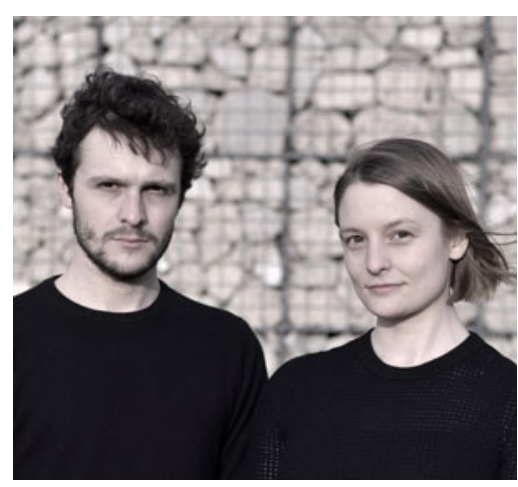

George Barton and Siwan Rhys (photo: Dejan Mrdja)

Gieshoff, CHAINES, Oliver

Sellwood and Nicholas Moroz.

Their CD of Oliver Leith's good day good day bad day bad day, released in August 2020 by Another Timbre, was described as 'bewitching ... deadpan, subversive, quietly anarchic, disarmingly heart-sore and sweet-sour' (Kate Molleson) and their binaural recording of Stockhausen's KONTAKTE, released in October 2019 by all that dust, was chosen by the Guardian as Album of the Week, Andrew Clements writing that the recording 'reveal[s] Stockhausen's musical thinking ... there may already be a number of recordings of this remarkable work, but theirs adds an extra dimension to it'.

Recent performances include Huddersfield Contemporary Music Festival, Vale of Glamorgan Festival, Presteigne Festival, Music at Oxford and the University of Birmingham and City University of London concert series. They have performed new works on the Music We'd Like to Hear podcast, BBC World Service's Arts Hour, BBC Radio 3's New Music Show, Night Tracks, In Tune, and Open Ear, RTÉ's Sounds Out and PBS Australia's The Sound Barrier.

Individually they perform as soloists and chamber musicians, and work with ensembles including the Colin Currie Group, London Sinfonietta, Birmingham Contemporary Music Group, LSO, CBSO, Britten Sinfonia, Aurora Orchestra, Riot Ensemble, Explore Ensemble, London Contemporary Orchestra and many others.

\section{How do you decide on new repertoire and commissions?}

We are very unsystematic and disorganised. We have no system for researching, and no scheduled discussions or meetings about new commissions. Partly this is because we live together, so we often talk about new musical discoveries in a casual way as a matter of course, and these gradually work themselves into plans and commissioning ideas; partly it comes from an unwillingness to transform the discovery of new music and new voices into a kind of duty that can kill the excitement of it (which is really the only meaningful 
barometer for us of whether it's a good idea or not). In a way there's a doublethink going on, where we try to remain listeners at heart, more hobbyists and music-lovers than part-time repertoire researchers. In practice that means that we listen to a great deal of music from outside our professional sphere, nurturing that feeling of pleasurable discovery and trying to keep the tank full of the milk of uncontaminated innocent curiosity!

\section{Can you identify a particular aesthetic that determines what and how you play?}

Perhaps it naturally follows from listening quite broadly and keeping things pretty unsystematic in our musical research that there's no crafted or planned aesthetic that we have across all our repertoire choices or performances. Having said that there are trends that one can probably see, although they're not deliberately crafted. We're both naturally drawn to music that has a certain intensity and focus to it on a moment-to-moment basis, rather than works that are extravagant or very gestural in their language. We both love playing extremely quietly, and we both have a long-standing interest in music that plays with the perception of time (indeed one of the first performances we gave together was playing Morton Feldman's For Philip Guston, which is a piece we love to perform, and we're really looking forward to recording a CD of Barbara Monk Feldman's music very soon).

But it's important to stay protean, because your creative duty must always be to tailor your playing to the piece and to the composer's wishes. Besides that, diverse musical experience is omnilaterally beneficial for our interpretations of all music. We're also really interested in the possibilities of collision between styles and genres and the kind of possibilities given by music that sits in the cracks a little bit. Recently we've been working on pieces with composers like CHAINES and Oliver Sellwood that have definite pop and IDM inflections, as well as music by Angharad Davies that incorporates free improvisation.

Doubtless devoting the ensemble entirely to one musical niche or sub-genre would make it more easily marketable, but our level of canniness is probably already amply demonstrated by the choice to form a piano and percussion duo in the first place, the instrumental duo that combines the two least portable instruments around.

It's inevitable, given the instruments you play, that there is a lot of furniture on stage. Do you worry about struggling to make a connection with the audience or being buried behind instruments?

It can be a concern. We take the approach of trying to draw people into the performance rather than attempting to dominate the stage particularly. Indeed we try to keep our own presence quite subtle and unimposing on stage. We both have a similar approach to technique that may sound self-evident: we try to remain still and relaxed other than the movements needed to produce sound. We've gradually developed a complementary technique of rhythmic cueing that is as functional and as minimal as possible, to the point that even close colleagues sometimes think we're not cueing one another or even not looking at each other on stage. To a degree this is simply about facilitating instrumental control by not having the gestures of 
communication or of 'expressivity' interfering with the mechanics of sound-production.

But equally there's probably a kind of pseudo-moralistic aspect at work, of not wanting to oversell our engagement with the music. Perhaps the attempt to pare the movements down is also the physical analogue of prizing intensity of focus over performative extravagance (or indeed interpretative extravagance). In any case, the movements inherently involved in producing a sound on our instruments are quite clearly visible and, as a result, performances can easily become visual shows as much as musical experiences, so perhaps it's also a wish that the visual aspect should not become over-dominant.

I love your recording of KONTAKTE. What drew you to the piece? How do you go about achieving the sense of 'contact' between what you play and what's in the tape part?

In fact KONTAKTE is one of the pieces that brought the duo together it was through and after working together on that piece, which was initially a one-off project, that we decided to play together more regularly.

As for your question about the 'contact' in the music, this is really the key to the power of the work. At its best moments the composition almost creates the sense that the electronics are like the sounds of previously unheard celestial bodies, and that these abstract planes of electronic tones actually bring the sounds of the acoustic instruments into being, like sudden lightning bolts or moments of acoustic immanence. In a way the composition is one of the high watermarks of a certain scientific or scientistic approach to composition of that era to take theoretical concepts regarding the construction and perception of sounds and convey an analysis or thesis regarding them through composition, aiming for a kind of gnostic understanding for the listener through immediate musical experience.

As for how we go about realising that feeling in performance, it may sound like quite a tall order, but practically speaking it's mainly a question of knowing the tape parts well enough to be able to play with them musically. That means knowing what is or should be in the foreground at any time, how (or whether) to blend the instrumental sounds with the tape by finding the right instrumental colour and, most obviously, playing at the precise right moment. This last point is not as trivial as it sounds - sometimes study of the score will reveal, for example, nested accelerandi or ritardandi where the beginning, end, and also some intermediate point in the process have to line up with electronic sounds in the tape. Some of the most exciting moments we had in rehearsal came from gradually honing these passages that were so difficult to calibrate and then, when the passage was finally in the slot, a resultant occurred that clearly showed this passage was designed to work just this way, like hearing some hocketing melody between instruments and tape that was latent in the composition and waiting to be brought out. 